\title{
Teaching Men of Color in the Community College: A Guidebook
}

"This timely volume can serve as an effective road map for community college faculty and instructional leaders in advancing the success of historically underrepresented and underserved men, particularly men of color. In this volume, Wood, Harris, and White offer research-based strategles that
demonstrated utllity in promoting effective teaching to men of color." demonstrated utllity in promoting effective teaching to men of color." of Community Colleges

"In light of President Obama's call for free community college education and launching of "My Brother's Keeper" initiatives, there is a multimillion-dollar effort to produce positive outcomes for underrepresented males of color and raise the profile of two-year institurtions that are the primary postsecondary pathway scores of men from racially/lethrically diverse communitles. As educators, policymakers, and researchers, wo must be about the business of engaging youth of color from boys to men across $P$-20 education. Teaching and learning are two concepts that are inexticably linked though in some conlexts loosely couplad. The Crical read the Tpectatons and authentic care are necessary precursors to effective teaching. The authors have crafted a timely gulde with great readability for accessing compeling examples of creating communlyy colloge environments that fostor PhD - Protoser of Higher Educat on University of Illinois at Urbana Champaign

"The success of men of color in education is a critical lssue facing our nation's community colleges. While our institutions provide unparalleled access to these men, challenges in promoting success necessitate practices that hollstically support their loaning. Tha volume responds to tils paradox by providin a step-by-step guide hat willompor

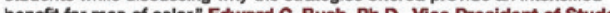
Services, Riverside Community College

\section{$\frac{\mathbf{M}}{\mathbf{P}}$ MONTEZUMA}

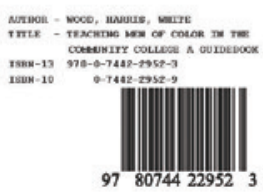

Sold By: Montezuma Publishing

ISBNs: 9780744229523,9780744237269

Publish Year: 2015

Language: English

Number of Pages: 108

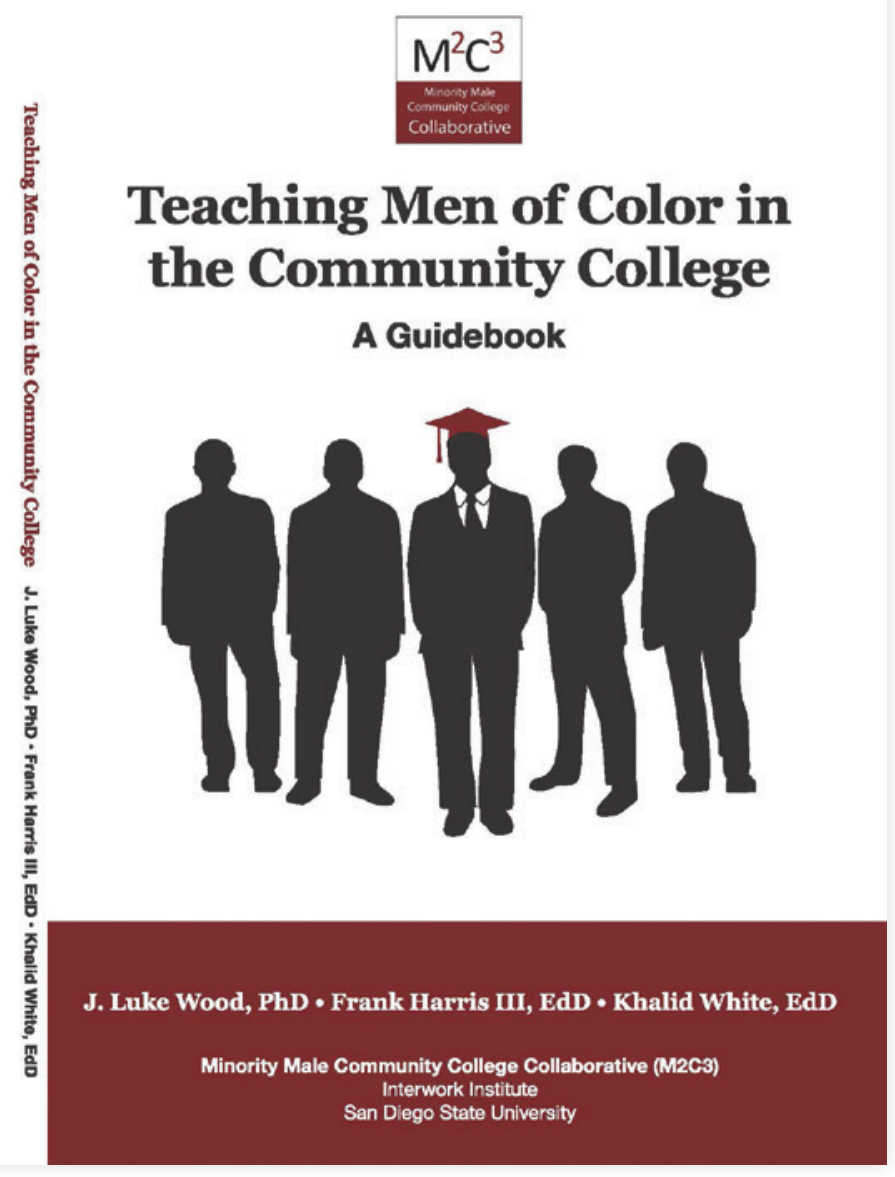

This guidebook articulates strategies for teaching men of color in community college. You will learn why implementing these approaches may take additional support from instructional leaders (e.g., department chairs, faculty development professionals, academic deans, vice presidents of instruction). Beyond providing recommendations for their peers, faculty leaders also extended suggestions for college leaders. Specifically, these suggestions focused on steps and strategies that instructional leaders could take to improve the success of men of color. To purchase or inquire about multiple copies click orders@montezumapublishing.com. 